\title{
LITOGEOQUÍMICA DO BATÓLITO ENDERBÍTICO-CHARNOCKÍTICO DO COMPLEXO JEQUIÉ, NA REGIÃO DE LAJE E MUTUIPE, BAHIA
}

\author{
ANDRÉ FORNARI* \& JOHILDO S.F. BARBOSA*
}

\begin{abstract}
LITHOGEOCHEMISTRY OF THE ENDERBITIC-CHARNOCKITIC B ATHOLITH OF THE JEQUIE COMPLEX, LAJE-MUTUIPE REGION, BAHIA. The granulitic rocks of the Laje-Mutuípe region are part of an enderbitic-charnockitic batholith that constitutes the most important segment of the Jequié Complex, situated in the southeast part of the State of Bahia. This plutonic body is considered to be intrusive in high grade metamorphic rocks made of acid and basic, and probably ortho-derivated banded granulites. Kinzigites, banded iron forraations, graphitites, garnetiferous quartzites, and granulitic migmatites are intercalated with these granulites. These plutonic rocks have been subjected to at least two deformation episodes in the ductile state: the first (Dl) tangential shearing stress, generated NW-verging overturned folds; the second (D2), also shearing, but of transcurrent nature, developed sub-vertical NNW-SSE foliations/bandings in the rocks. The enderbites, charno-enderbites and charnockites are intermediate and acid rocks, that represent two calc-alkaline series. The first is characterized by lower contents of Ti, Fe, K, P, Rb, Zr, Ba, Y and REE, than the second, which is chemically more mature and probably intrusive into the first. The crystallisation age of these plutonic rocks, obtained through U/Pb measurements in zircons, by the "SHRIMP" (Sensitive High Resolution lonic Microprobe) technique, is situated between 2,700 and 2,800 Ma, being therefore considered of Archean age.
\end{abstract}

Keywords: Enderbitic-charnockitic rocks, granulitic metamorphism, Archean, Calc-alkaline series.

\begin{abstract}
RESUMO As rochas granulíticas, da região de Laje e Mutuípe, fazem parte de um batólito enderbíticocharnockítico, que constitui o segmento mais importante do Complexo Jequié, situado no sudeste da Bahia. Este corpo plutônico é considerado intrusivo em rochas metamórficas de alto grau, consistindo de granulitos bandados, ácidos e básicos, provavelmente ortoderivados, aos quais encontram-se intercalados tectonicamente com kinzigitos, formações ferríferas, grafititos, quartzitos granatíferos, além de migmatitos granulíticos. Essas rochas plutônicas, na região em foco, sofreram pelo menos dois episódios deformacionais no estado dúctil: 0 primeiro (Dl), cisalhante e tangencial, gerou dobras deitadas com vergência para NW; o segundo (D2), também cisalhante mas transcorrente, desenvolveu nas rochas foliacões/bandamentos subverticais de direção predominante NNW-SSE. Os enderbitos, charno-enderbitos e charnockitos representam duas séries cálcioalcalinas. A primeira caracteriza-se por possuir baixos teores de Ti, Fe, K, P, Rb, Zr, Ba, Y e ETR. A segunda é mais madura quimicamente e intrusiva na primeira. A idade de cristalização dessas rochas plutônicas, obtidas por meio de medidas U/Pb, em zircões, pela "SHRIMP" (Sensitive High Resolution lonic Microprobe), situa-se entre 2.700 e $2.800 \mathrm{Ma}$, sendo assim consideradas do Arqueano.
\end{abstract}

Palavras-chave: Rochas enderbíticas-charnockíticas, Arqueano, metamorfismo granulítico, séries cálcioalcalinas.

INTRODUÇÃ̃o O Complexo de Jequié (Cordani 1973) ou Domínio Jequié-Mutuípe-Maracás (Barbosa et al. 1992) é formado por dois conjuntos litológicos principais: (i) rochas plutônicas ácidas e intermediárias, enderbíticascharnockíticas, reequilibradas na fácies granulito e (ii) granulitos básicos e ácidos, provavelmente ortoderivados, intercalados com kinzigitos, formação ferrífera, grafitito e quartzito granatífero. Este último conjunto, às vezes, mostra-se migmatizado na fácies granulito e penetrado por granitos de anatexia (Barbosa 1986).

Inúmeros trabalhos foram executados no Complexo Jequié, dentre os quais podemos citar aqueles de Sighinolfi (1970,1971), Mascarenhas (1973), Cordani (1973), Pedreira et al (1975), Sighinolfi \& Sakai (1977), Mascarenhas (1979), Cordani \& lyer (1979), Sighinolfi et ai (1981), Mascarenhas (1981), Miranda et al (1982), Lima et al (1982), Costa \& Mascarenhas (1982), Oliveira \& Lima (1982), Oliveira et al (1982), lyer et al (1984), Delhal \& Demaife (1985) e lyer et al (1987). Entretanto, apesar dessas pesquisas terem contribuído sobremaneira para o conhecimento da geologia da região, de maneira geral, ou elas situaram-se em áreas isoladas ou foram sempre de caráter específico. Mapeamentos regionais acoplados com a geoquímica de rocha, visando a definição dos protólitos pré-granulitização e sua cartografia, foram iniciados somente a partir de 1986. Entre esses trabalhos, destacaram-se os de Barbosa (1986, 1990) e Barbosa \& Fonteilles (1989), que conseguiram separar geoquimicamçnte e petrograficamente os dois conjuntos litológicos citados acima. Além desses, recentemente, uma síntese sobre os terrenos de alto grau do Cráton do São Francisco, incluindo os aqui abordados, foi efetuada por Figueiredo \& Barbosa (1993), que também contribuiu para o avanço dos conhecimentos da geologia da região.

A área de pesquisa está situada no domínio (i), sobre as rochas enderbíticas-charnockíticas da região de Laje e Mu-tuípe (Fig. 1). Nela, Fornari (1992) e Fornari \& Barbosa (1992 a,b) aprofundaram as pesquisas de Barbosa $(1986,1990)$ e Barbosa \& Fonteilles $(1989)$, com um mapeamento geológico na escala 1:50.000, acompanhado de minucioso estudo petrográfico e petroquímico. Com isso, foi possível separar e classificar as unidades litológicas que compõem o corpo rochoso plutônico granulitizado e, a partir daí, empre-ender estudos, utilizando elementos químicos, maiores, menores e traços, incluindo os Terras Raras. Isto permitiu, não só visualizar o comportamento desses elementos frente aos processos de diferenciação, mas também caracterizar a filiação geoquímica do magma gerador dos protólitos em questão. Este trabalho é uma síntese das pesquisas litogeoquímicas realizadas pêlos últimos autores, sobretudo aquelas de Fornari (1992). \footnotetext{
* Curso de Pós-Graduacão em Geologia, Instituto de Geociências, Universidade Federal da Bahia, Rua Caetano Moura, 123, Federação, CEP 40210-340,
Salvador, Bahia, Brasil
} 


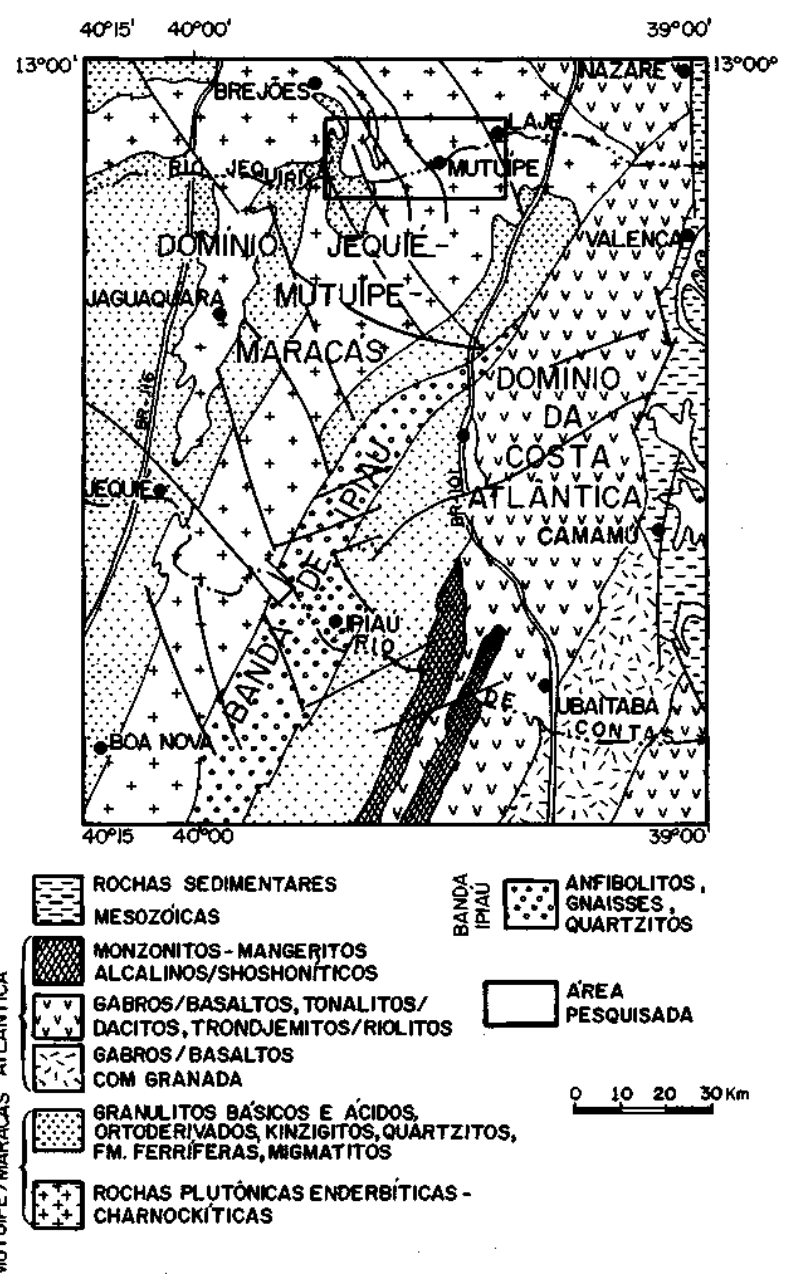

Figura l-Mapa geológico regional e localização da área pesquisada (simplificado de Barbosa 1986)

Figure 1 - Regional geological sketch map and location of the research área (simplified from Barbosa 1986)

GEOLOGIA LOCAL E PETROGRAFIA Os enderbitos, charno-enderbitos e charnockitos, que constituem neste trabalho o domínio (i), estão localizados na parte central e leste da área estudada. Formam um batólito, com características relativamente homogéneas que, parece, intrudiu os granulitos básicos e ácidos ortoderivados, kinzigitos, formação ferrífera, quartzito granatífero e grafitito, situados a oeste, no denominado domínio (ii) (Fig. 2). Esta intrusão enderbítica-charnockítica, de extensão regional, parece ter ocorrido durante episódio de meta-morfismo granulítico, que atingiu boa parte do sudeste da Bahia.

No domínio (ii), o relevo é mais acidentado, possuindo, na sua maior extensão, estruturação complexa, com foliação-bandamento de direções variadas desde E-W até N-S. A presença de formas arredondadas, dômicas, é relativamente comum nesse domínio, sendo observadas, sobretudo, em escala regional.

No domínio (i), objeto deste trabalho, o relevo é menos acidentado, com o trend principal das rochas situado na direção NNW-SSE, embora localmente também se verifique foliação/bandamento com direções N-S e NE-SW. Dois episódios deformacionais dúcteis orientaram a foliaçãobandamento segundo as direções mencionadas. O primeiro (D1) gerou a foliação Sn, a qual, com a continuação dos esforços, foi progressivamente dobrada de forma apertada a isoclinal, com vergência para NW. Desenvolveu, nas dobras deitadas, resultantes do primeiro episódio, planos axiais de atitude predominante N10-40E; 40-50SE, preservados prin- cipalmente nos arredores da cidade de Laje (Fig. 2). $\mathrm{O}$ segundo episódio deformacional (D2), contínuo ao primeiro, cisalhante dúctil, transcorrente, é predominante na área. Gerou foliações $\mathrm{Sn}+1$, de direção preferencial N10$30 \mathrm{~W}$, com mergulhos variáveis: na parte oriental da área mostram inclinações predominantes entre $60-80 \mathrm{NE}$; na parte central, nas proximidades de Mutuípe, são verticais; e, na parte ocidental, seus mergulhos se invertem, passando a ter inclinações preponderantes em torno de 60-80SW ( Fornari \& Barbosa 1992a,b, Fornari 1992). Sobre os planos de foliação/bandamento $\mathrm{Sn}+1$, as lineações de estiramento mineral $\left(\mathrm{L}_{\mathrm{x}}\right)$ existentes possuem, na sua maioria, caimentos entre $5^{\circ}$ e $20^{\circ}$ no rumo N10-30W.

Os charnockitos, charno-enderbitos e enderbitos possuem coloração cinza-escura a cinza-esverdeada, na sua mai-oria, embora possam também ser observadas cores rosadas, produto de leve alteração, principalmente em alguns aflora-mentos de charnockitos. Ocorrem tanto estruturas maciças quanto gnáissicas, sendo que, nessas últimas, verifica-se intercalações de níveis félsicos de minerais quartzo feldspáticos com níveis máficos, onde predominam piroxênios, hornblenda e opacos, com alguma biotita existindo subordinadamente. Texturalmente, essas rochas plutônicas mostram-se com granulação média a grossa, exibindo, em alguns afloramentos, porfiroclastos de mesopertita, feldspato alcalino pertítico, plagioclásio e mais raramente piro-xênios. A forma dos porfiroclastos, de maneira geral, são sigmoidais e lenticulares, mostrando estarem afetados pelo cisalhamento dúctil, superimposto. Algumas vezes, no en-tanto, podem ser observadas as formas originais retangulares. A mineralogia dessas rochas é composta basicamente por mesopertita e feldspato alcalino pertítico, plagioclásio com teores de An em torno de 30-35\%, quartzo, além de ortopiroxênio (hiperstênio), clinopiroxênio (augita), hornblenda marrom e opacos (ilmenita e magnetita). Ocorre crescimento percentual de plagioclásios e piroxênios dos charnockitos para os enderbitos, ao passo que, em direção aos charnockitos, aumentam as proporções de feldspato alcalino e mesopertitas (Fig. 3, Tab. 1). Os minerais acessórios são o zircão, opacos e a apatita. Observam-se, ainda, opacos, biotita, sericita, uralita, clprita e bastita como minerais secundários formados, principalmente, a partir da desestabilização dos piroxênios.

A presença de veios de quartzo leitoso e, principalmente, de veios pegmatíticos é comum em toda a área. Estes últimos possuem composição semelhante à da rocha hospedeira. Os pegmatitos salientam-se no seio da rocha, devido a sua textura grossa com cristais que chegam a atingir dimensões centimétricas, como é o caso de alguns piroxênios que medem cerca de $3 \mathrm{~cm}$ e certos feldspatos alcalinos pertíticos e mesopertitas, que podem alcançar até $5 \mathrm{~cm}$ de comprimento. A relação temporal com os episódios deformacionais mostra que existem, pelo menos, duas gerações de veios pegmatíticos: uma primeira pré ou sin-deformacional, que aparece dobrada ou estirada paralelamente à foliação e, uma segunda, nitidamente pós-deformaeional, cortando tanto os veios anteriores, como a foliação-bandamento impressa na rocha.

Ainda, inserido nesses plutonitos enderbíticos-charnockíticos, são encontrados enclaves máficos de composição gabro-norítica, com textura granoblástica poligonal, fina a média. Esses enclaves, na sua maioria, não possuem comprimento superior a $50 \mathrm{~cm}$, mostrando formas lenticulares e sigmoidais, por vezes apresentando-se parcialmente assimiladas nas bordas, pela rocha encaixante. A mineralogia principal é formada por plagioclásio, clinopiroxênio, hornblenda, ortopiroxênio e opacos. Como minerais secundários, ocorrem não só biotita, mas também opacos e hornblendas, produtos da alteração dos piroxênios. Como acessório, foi identificada a apatita. 
Tabela 1 -Porcentagem modal dos minerais das rochas charnokíticas, charno-enderbíticas das séries "alto e baixo"

Table l - Mineral modal percentage of charnockitic, charno-enderbitic and enderbitic rocks of the "high and low Ti series"

\begin{tabular}{|c|c|c|c|c|c|c|}
\hline & $\begin{array}{c}\text { ED1 } \\
\text { JA-39 }\end{array}$ & $\begin{array}{c}\text { ED2 } \\
\text { JA-35 }\end{array}$ & $\begin{array}{c}\text { CHED1 } \\
\text { JA-21 }\end{array}$ & $\begin{array}{c}\text { CHED2 } \\
\text { JA }-42\end{array}$ & $\begin{array}{c}\mathrm{CH} 1 \\
\mathrm{JA}-38\end{array}$ & $\begin{array}{c}\mathrm{CH} 2 \\
\mathrm{BJ}-143\end{array}$ \\
\hline Plagioclásio & $57 \%$ & $45 \%$ & $56 \%$ & $50 \%$ & $8 \%$ & $\operatorname{tr}$ \\
\hline K-Feldspato & $4 \%$ & $\operatorname{tr}$ & $6 \%$ & $\operatorname{tr}$ & $\mathrm{tr}$ & tr \\
\hline Mesopertita & - & $10 \%$ & - & $12 \%$ & $47 \%$ & $62 \%$ \\
\hline Quartzo & $32 \%$ & $28 \%$ & $36 \%$ & $30 \%$ & $42 \%$ & $29 \%$ \\
\hline Hiperstênio & $5 \%$ & $6 \%$ & $\operatorname{tr}$ & $4 \%$ & $3 \%$ & $1 \%$ \\
\hline Augita & $1 \%$ & $6 \%$ & - & tr & - & $1 \%$ \\
\hline Hornb, Marrom & - & $3 \%$ & - & $2 \%$ & - & $5 \%$ \\
\hline Opacos & $1 \%$ & $2 \%$ & - & $2 \%$ & - & $2 \%$ \\
\hline Zircão & tr & $\operatorname{tr}$ & $\operatorname{tr}$ & tr & - & - \\
\hline Apatita & $\operatorname{tr}$ & $\operatorname{tr}$ & - & tr & tr & $\operatorname{tr}$ \\
\hline Hornb, Verde & $\operatorname{tr}$ & - & - & tr & - & - \\
\hline Biotita & $\operatorname{tr}$ & $\operatorname{tr}$ & $2 \%$ & - & - & - \\
\hline Opac, Secund, & $\operatorname{tr}$ & $\operatorname{tr}$ & $\operatorname{tr}$ & tr & $\operatorname{tr}$ & tr \\
\hline Clorita & $\operatorname{tr}$ & - & - & tr & - & $\operatorname{tr}$ \\
\hline Uralita & $\operatorname{tr}$ & $\operatorname{tr}$ & - & $\operatorname{tr}$ & - & - \\
\hline Bastita & $\operatorname{tr}$ & $\operatorname{tr}$ & $\operatorname{tr}$ & $\operatorname{tr}$ & $\operatorname{tr}$ & $\operatorname{tr}$ \\
\hline
\end{tabular}

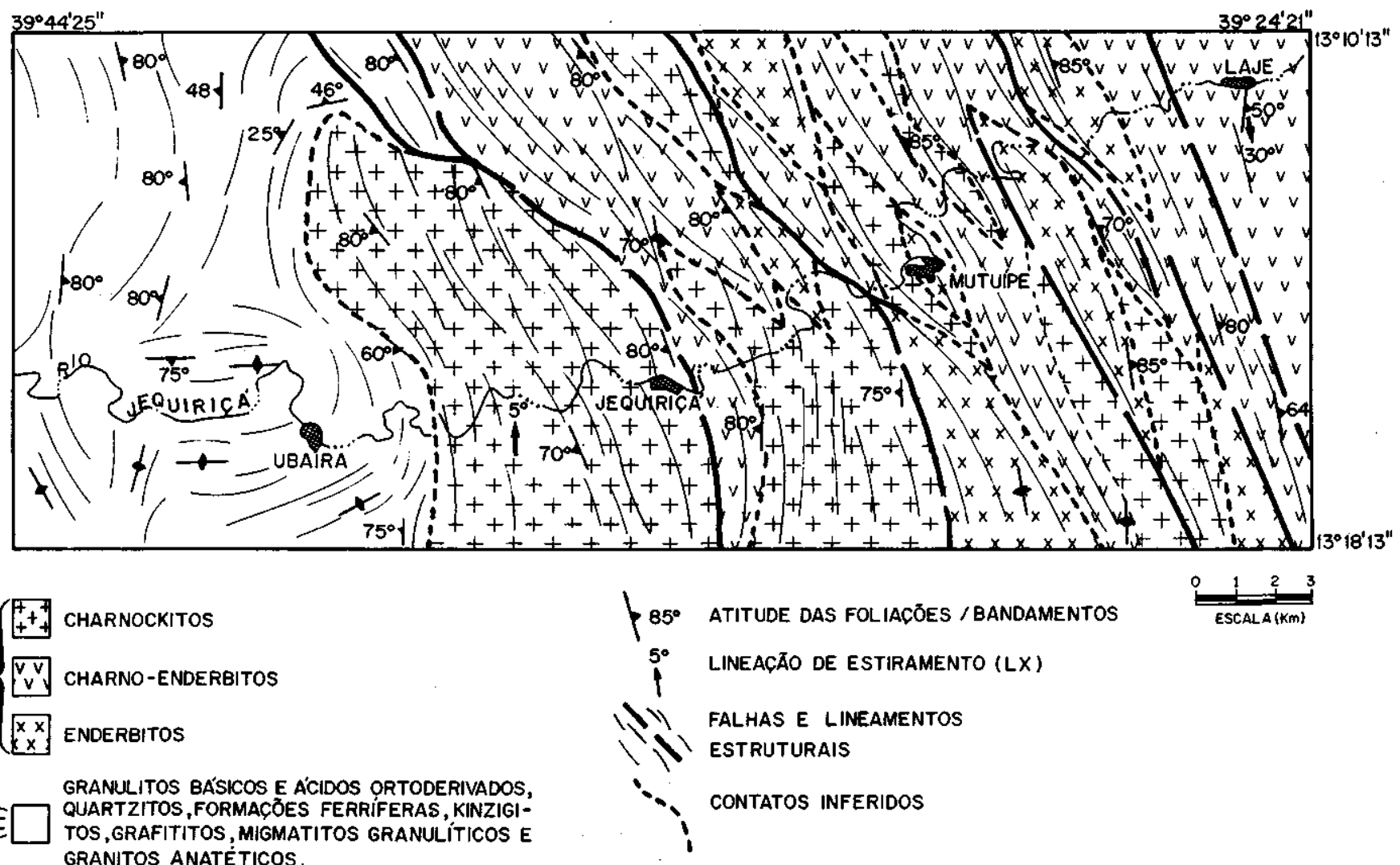

Figura 2 - Mapa geológico da área pesquisada (simplificado de Fornari 1992)

Figure 2- Geological map of the research área (simplified from Fornari 1992)

LITOGEOQUÍMICA Para os estudos litogeoquímicos, foram utilizadas 38 análises químicas de elementos maiores, menores e traços, e nove determinações de Elementos Terras Raras (Tab. 2). Os métodos analíticos utilizados nas amostras com prefixo "JA" foram aqueles de rotina dos labo- ratórios da Geologia e Sondagens S.A. (Geosol), que consiste em utilizar a Fluorescência de Raios X para deter-minar os elementos maiores e traços, menos $\mathrm{Na}$ e $\mathrm{K}$, que foram analisados por Absorção Atómica, e a Espectrometria de Plasma ICP, para os Elementos Terras Raras. As amostras 


\begin{tabular}{|c|c|c|c|c|c|c|c|c|c|c|c|c|c|c|c|c|c|c|c|c|c|c|c|c|c|c|}
\hline & $\begin{array}{l}\text { ED2 } \\
\text { JA-3 }\end{array}$ & $\begin{array}{l}\text { EDI } \\
\text { JA-14 }\end{array}$ & $\begin{array}{c}\text { EDI } \\
\text { JA-40 }\end{array}$ & $\begin{array}{c}\text { ED2 } \\
64\end{array}$ & $\begin{array}{l}\text { ED2 } \\
\text { SM-6 }\end{array}$ & $\begin{array}{c}\text { ED1 } \\
\text { 3A-39 }\end{array}$ & $\begin{array}{c}\text { ED2 } \\
\text { JA-33 }\end{array}$ & $\begin{array}{l}\text { ED2 } \\
\text { 3-A }\end{array}$ & $\begin{array}{l}\text { ED2 } \\
3-B\end{array}$ & $\begin{array}{l}\text { ED2 } \\
\text { SM-9 }\end{array}$ & $\begin{array}{c}\text { ED2 } \\
\text { JA-35 }\end{array}$ & $\begin{array}{l}\text { CHED2 } \\
\text { SM-3 }\end{array}$ & $\begin{array}{c}\text { CHED2 } \\
204 \mathrm{~B}\end{array}$ & $\begin{array}{l}\text { CHED2 } \\
\text { JA.22 }\end{array}$ & $\begin{array}{c}\text { CHEDI } \\
\text { JA-2I }\end{array}$ & $\begin{array}{c}\text { CHEDI } \\
\text { JA.II }\end{array}$ & $\begin{array}{c}\text { CHED2 } \\
204-A\end{array}$ & $\begin{array}{c}\text { CHED2 } \\
\text { SM-4 }\end{array}$ & $\begin{array}{c}\text { CHED2 } \\
\text { SM-5 }\end{array}$ & $\begin{array}{l}\text { CHED2 } \\
\text { JA-44 }\end{array}$ & $\begin{array}{c}\text { CHED2 } \\
\text { JA-42 }\end{array}$ & $\begin{array}{l}\text { CHED2 } \\
\text { BJ-144 }\end{array}$ & $\begin{array}{c}\text { CHED2 } \\
J_{A-43}\end{array}$ & $\begin{array}{l}\text { CHEDI } \\
\text { BJ.185 }\end{array}$ & $\begin{array}{c}\text { CHEDI } \\
\text { SM-2 }\end{array}$ & $\begin{array}{l}\text { CHEDI } \\
\text { SM-I }\end{array}$ \\
\hline$\overline{\mathrm{SiO}_{2}}$ & 53,9 & 59,1 & 59,4 & 64,04 & 64,33 & 64,8 & 64.9 & 65,0 & 65,29 & 66,17 & 66,4 & 66,82 & 66,88 & 67,2 & 67,5 & 67,5 & 67.65 & 67,68 & 67,83 & 68.5 & 68,6 & 68,6 & 69,0 & 69,8 & 69,9 & 70,52 \\
\hline $\mathrm{TrO}_{2}$ & 1,9 & 0,83 & 0,77 & 1,38 & 1,24 & 0,55 & 1,2 & 1,33 & 1,23 & 1,11 & 1,1 & 1,15 & 1,00 & 1,1 & 0,39 & 0.45 & 1,03 & 0,93 & 0,98 & 0,79 & 1,1 & 0,72 & 0,78 & 0,31 & 0,25 & 0,26 \\
\hline $\mathrm{Al}_{2} \mathrm{O}_{3}$ & 16,9 & 17,1 & 18,0 & 13,3 & 3,37 & 15,9 & 13,4 & 12,65 & 12,87 & 13,83 & 13,5 & 13,31 & 12,27 & 13,5 & 16,0 & 15,1 & 12,28 & 13,23 & 12,96 & 13,5 & 12,8 & 13,0 & 13,2 & 15,4 & 15,23 & 15,43 \\
\hline $\mathrm{Fe}_{2} \mathrm{O}_{3}$ & 5,2 & 3,3 & 3,0 & 1,58 & $7,67^{*}$ & 1,8 & 2.5 & 2,84 & 3,96 & $6,07 *$ & 0,9 & $6,96^{*}$ & 2,16 & 2,6 & 1,7 & 2.2 & 2,44 & $5,83^{*}$ & $5,30^{*}$ & 2,1 & 2,3 & 1,1 & 1,5 & 0,4 & $2,17^{*}$ & $2,09 *$ \\
\hline $\mathrm{FeO}$ & 4,3 & 3,0 & 2,9 & 5,58 & $6,9^{*}$ & 2.2 & 4,4 & 4,99 & 3,58 & $5,46^{*}$ & 4,7 & $6,26^{*}$ & 3,75 & 3,7 & 1,9 & 2,1 & 4,10 & $5,24^{*}$ & $4,77^{*}$ & 3,0 & 4,0 & 3,46 & 3,4 & 1,8 & $1,95^{*}$ & $1,88^{*}$ \\
\hline $\mathrm{MnO}$ & 0,13 & 0,09 & 0,09 & 0,11 & 0,1 & 0,08 & 0,1 & 0,08 & 0,08 & 0,09 & 0.09 & 0,12 & 0,08 & 0,09 & 0,06 & 0,04 & 0,1 & 0,1 & 0,08 & 0,11 & 0,11 & 0,06 & 0,09 & 0,04 & 0,03 & 0,03 \\
\hline $\mathrm{MgO}$ & 1,8 & 3,0 & 2,8 & 1,52 & 1,29 & 2,2 & 1,2 & 1,14 & 1,07 & 1,16 & 1,2 & 1,41 & 0,9 & 1,1 & 1,4 & 0,8 & 0,68 & 0,98 & 1,02 & 0,96 & 1,1 & 0,77 & 0,91 & 1,1 & 0,92 & 0,92 \\
\hline $\mathrm{CaO}$ & 7,3 & 6.3 & 6,0 & 4,31 & 4,0 & 4,2 & 4.0 & 3,94 & 4,2 & 3,1 & 3,7 & 3,39 & 3,13 & 3,8 & 3,8 & 2,9 & 2.74 & 3,23 & 3,00 & 2,9 & 3,3 & 2,5 & 2,9 & 3,4 & 3,01 & 2,98 \\
\hline $\mathrm{Na}_{2} \mathrm{O}$ & 4,2 & 4,6 & 4,7 & 3,2 & 3,03 & 4,4 & 3,0 & 3,0 & 3,17 & 2,97 & 3,2 & 3,26 & 2,79 & 3,3 & 4,6 & 4,1 & 2,93 & 3,33 & 3,04 & 3,4 & 3,4 & 4,0 & 3,1 & 5,1 & 4,86 & 4,93 \\
\hline $\mathrm{K}_{2} \mathrm{O}$ & 2,6 & 1,8 & 1,2 & 3,1 & 3,48 & 2,8 & 3.9 & 3,74 & 3,26 & 3,93 & 3,9 & 2,46 & 4,95 & 2,4 & 2,0 & 3,1 & 4,2 & 2,78 & 4,17 & 3,6 & 2,3 & 4,1 & 4,1 & 1,8 & 1,96 & 1,87 \\
\hline $\mathrm{P}_{2} \mathrm{O}_{3}$ & 1,2 & 0,35 & 0,39 & 0,46 & 0,39 & 0.38 & 0,51 & 0,51 & 0,48 & 0,37 & 0,39 & 0,37 & 0,31 & 0,35 & 0,15 & 0,25 & 0,21 & 0,3 & 0,33 & 0,3 & 0,35 & 0,18 & 0,25 & 0.13 & 0,08 & 0,08 \\
\hline TOTAL & 99.5 & 99,81 & 99,25 & 99,05 & 98,9 & 99,31 & 99,11 & 99,22 & 99,19 & 98,8 & 99,08 & 99,25 & 98,22 & 99,14 & 99,5 & $\mathbf{9 9 , 2 9}$ & 98,33 & 98,39 & 98,71 & 99,16 & 99,36 & 98,49 & 99,23 & 99,28 & 98,41 & 99,11 \\
\hline $\mathbf{R b}$ & 42 & 24 & 14 & 64 & 84 & 64 & $n$ & 93 & 92 & 93 & 83 & 55 & 113 & 43 & 54 & 58 & 91 & 70 & 83 & 94 & 57 & 62 & 120 & 39 & 32 & 43 \\
\hline Sr & 290 & 520 & 920 & 248 & 240 & 710 & 300 & 278 & 287 & 333 & 340 & 307 & 293 & 270 & 450 & 680 & 240 & 288 & 336 & 280 & 300 & 300 & 210 & 860 & 670 & 668 \\
\hline$z$ & 640 & 310 & 210 & 540 & 417 & 250 & 550 & 422 & 400 & 468 & 440 & 432 & 372 & 400 & 160 & 740 & 455 & 373 & 333 & 470 & 640 & 440 & 390 & 140 & 84 & 78 \\
\hline$Y$ & 56 & 26 & 31 & - & 55 & 30 & 61 & - & - & 29 & 43 & 32 & - & 49 & 18 & 10 & - & 31 & 27 & 48 & 49 & 27 & 69 & 14 & 7,9 & 5.8 \\
\hline $\mathbf{B a}$ & 670 & 720 & 760 & - & 1339 & 910 & 1480 & 1936 & 1448 & 1718 & 1700 & 984 & 2105 & 1230 & 700 & 1470 & 1618 & 945 & 668 & 1400 & 960 & 1460 & 920 & 720 & 788 & 701 \\
\hline La & - & - & - & - & - & 46,84 & - & - & 75,32 & - & - & - & 102.97 & - & - & 64,98 & - & - & - & 42,08 & - & - & - & - & - & - \\
\hline $\mathrm{Ce}$ & - & - & - & - & - & 106.20 & - & - & 146,71 & - & - & - & 194,10 & - & - & 122,70 & - & - & - & 95,10 & - & - & - & - & - & - \\
\hline $\mathrm{Nd}$ & - & - & - & - & - & 46,15 & - & - & 68,07 & - & - & - & 85,70 & - & - & 47,44 & - & - & - & 44,10 & - & - & - & - & - & - \\
\hline $\mathrm{Sm}$ & - & - & - & - & - & 8,72 & - & - & 12,82 & - & - & - & 15,17 & - & - & 6,83 & - & - & - & 8,65 & - & - & - & - & - & - \\
\hline Eu & - & - & - & - & - & 1,76 & - & - & 2,92 & - & - & - & 2,91 & - & - & 1,27 & - & - & - & 2,00 & - & - & - & - & - & - \\
\hline Gd & - & - & - & - & - & 6,02 & - & - & 9,38 & - & - & - & 10,62 & - & - & 4,01 & - & - & - & 6,65 & - & - & - & - & - & - \\
\hline Dy & - & - & - & - & - & 4,09 & - & - & 7,06 & - & - & - & 7,66 & - & - & 1,97 & - & - & - & 6.05 & - & - & - & - & - & - \\
\hline Ho & - & - & - & - & - & 0,83 & - & - & - & - & - & - & - & - & - & 0,33 & - & - & - & 1,20 & - & - & - & - & - & - \\
\hline Er & - & - & - & - & - & 2,27 & - & - & 3,22 & - & - & - & 3,44 & - & - & 0,80 & - & - & - & 3,22 & - & - & - & - & - & - \\
\hline Yb & - & - & - & - & - & 1,74 & - & - & 2,87 & - & - & - & 3,03 & - & - & 0,55 & - & - & - & 2,59 & - & - & - & - & - & - \\
\hline Lu & - & - & - & - & - & 0,33 & - & - & 0,40 & - & - & - & 0,43 & - & - & 0,08 & - & - & - & 0,39 & - & - & - & - & - & - \\
\hline
\end{tabular}


Tabela 2 - Continuação

Table 2 - Continuation

\begin{tabular}{|c|c|c|c|c|c|c|c|c|c|c|c|c|}
\hline & $\begin{array}{c}\mathrm{CH} 2 \\
\mathrm{SM}-14\end{array}$ & $\begin{array}{c}\text { CH1 } \\
\text { SM-13 }\end{array}$ & $\begin{array}{c}\mathrm{CH} 1 \\
\mathrm{JA}-38\end{array}$ & $\begin{array}{c}\mathrm{CH} 2 \\
\mathrm{SM}-12\end{array}$ & $\begin{array}{c}\mathrm{CH} 2 \\
\text { BJ-143 }\end{array}$ & $\begin{array}{c}\mathrm{CH} 2 \\
\mathrm{JA}-48\end{array}$ & $\begin{array}{c}\mathrm{CH} 2 \\
\mathrm{JA}-50\end{array}$ & $\begin{array}{c}\mathrm{CH} 2 \\
\mathrm{SM}-11\end{array}$ & $\begin{array}{c}\mathrm{CH} 1 \\
\mathrm{JA}-46\end{array}$ & $\begin{array}{c}\mathrm{CH} 1 \\
\mathrm{JA}-49\end{array}$ & $\begin{array}{c}\mathrm{CH} 1 \\
\text { SM-10 }\end{array}$ & $\begin{array}{c}\mathrm{CH} 1 \\
\text { JA-19 }\end{array}$ \\
\hline $\mathrm{SiO}_{2}$ & 70,66 & 71,24 & 71,8 & 72,02 & 72,4 & 72.5 & 72,9 & 73,05 & 73,3 & 73,9 & 73,9 & 74,4 \\
\hline $\mathrm{TiO}_{2}$ & 0,61 & 0,23 & 0,32 & 0,53 & 0,48 & 0,47 & 0,46 & 0,44 & 0,14 & 0,11 & 0,19 & 0,17 \\
\hline $\mathrm{Al}_{2} \mathrm{O}_{3}$ & 12,85 & 14,98 & 14,4 & 11,94 & 12,0 & 12,4 & 12,2 & 12,50 & 14,3 & 13,9 & 13,44 & 13,7 \\
\hline $\mathrm{Fe}_{2} \mathrm{O}_{3}$ & $4,36^{*}$ & $1,72^{*}$ & 0,45 & $4,42^{*}$ & 1,2 & 1,5 & 1,2 & $2,98^{*}$ & 0,27 & 0,1 & $1,70^{*}$ & 0,54 \\
\hline $\mathrm{FeO}$ & $3,92^{*}$ & $1,55^{*}$ & 1,4 & $3,98 *$ & 2,01 & 2,0 & 2,2 & $2,68 *$ & 1,2 & 0,79 & $1,53^{*}$ & 0,5 \\
\hline MnO & 0,05 & 0,03 & 0,03 & 0,07 & 0,05 & 0,06 & 0,05 & 0,03 & 0,04 & 0,01 & 0,03 & 0,01 \\
\hline $\mathrm{MgO}$ & 0,5 & 0,74 & 0,66 & 0,32 & 0,5 & 0,4 & 0,38 & 0,41 & 0,64 & 0,34 & 0,19 & 0,27 \\
\hline $\mathrm{CaO}$ & 1,65 & 2,21 & 1,5 & 1,29 & 1,3 & 1,3 & 1,4 & 1,69 & 1,8 & 1,2 & 1,24 & 1,5 \\
\hline $\mathrm{Na}_{2} \mathrm{O}$ & 2,84 & 4,82 & 3,0 & 2,69 & 3,0 & 2,9 & 2,7 & 2,54 & 4,6 & 3,5 & 3,53 & 3,2 \\
\hline $\mathrm{K}_{2} \mathrm{O}$ & 5,86 & 2,57 & 5,8 & 5,41 & 6,5 & 5,6 & 5,6 & 4,88 & 3,3 & 5,5 & 4,71 & 5,1 \\
\hline $\mathrm{P}_{2} \mathrm{O}_{3}$ & 0,08 & 0,06 & 0.12 & 0,08 & 0,07 & 0,10 & 0,1 & 0,11 & 0,05 & 0,08 & 0,04 & 0,05 \\
\hline TOTAL & 99,46 & 98,6 & 99,48 & 98,77 & 99,51 & 99,23 & 99,19 & 98,63 & 99,64 & 99,43 & 98,97 & 99,44 \\
\hline $\mathrm{Rb}$ & 377 & 79 & 170 & 188 & 280 & 360 & 380 & 145 & 98 & 210 & 256 & 91 \\
\hline $\mathrm{Sr}$ & 67 & 375 & 320 & 52 & 58 & 90 & 85 & 133 & 350 & 440 & 76 & 270 \\
\hline $\mathrm{Zr}$ & 479 & 91 & 290 & 504 & 230 & 610 & 870 & 202 & 120 & 93 & 142 & 190 \\
\hline $\mathbf{Y}$ & 61 & 5,4 & 18 & 76 & 68 & 91 & 85 & 38 & 12 & 12 & 29 & 10 \\
\hline $\mathbf{B a}$ & 726 & 597 & 2180 & 781 & 900 & 670 & 630 & 780 & 660 & 1520 & 551 & 1090 \\
\hline La & - & - & - & - & - & 141,30 & - & - & 22,72 & 17,24 & - & 45,42 \\
\hline $\mathrm{Ce}$ & - & - & - & - & - & 217,10 & - & - & 46.58 & 34,63 & - & 91,97 \\
\hline Nd & - & - & - & - & - & 78,45 & - & - & 15,97 & 12,05 & - & 30,50 \\
\hline $\mathrm{Sm}$ & - & - & 一 & - & - & 15,12 & - & - & 2,90 & 2,15 & - & 5,33 \\
\hline $\mathrm{Eu}$ & - & - & - & - & - & 1,71 & - & - & 0,54 & 0,65 & - & 0,93 \\
\hline $\mathrm{Gd}$ & - & - & - & - & - & 11,33 & - & - & 2,00 & 1,32 & - & 2,99 \\
\hline Dy & - & - & - & - & - & 12,54 & - & - & 1,15 & 0,68 & - & 1,10 \\
\hline Ho & - & - & - & - & - & 2,62 & - & - & 0,22 & 0,13 & - & 0,20 \\
\hline Er & - & - & - & - & - & 7,69 & - & - & 0,55 & 0,34 & - & 0,47 \\
\hline $\mathrm{Yb}$ & - & - & - & - & - & 6,97 & - & - & 0,51 & 0,23 & - & 0,22 \\
\hline $\mathbf{L u}$ & - & 一 & - & - & - & 0,95 & - & - & 0,12 & 0,10 & - & 0,11 \\
\hline
\end{tabular}

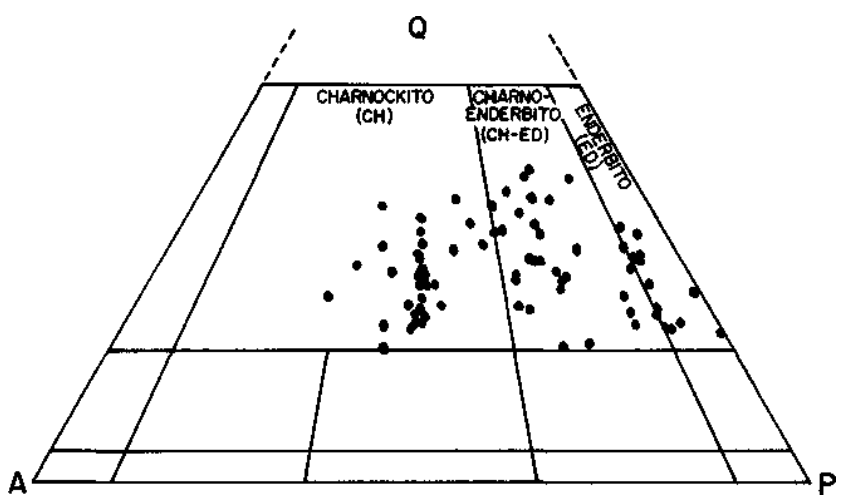

Figura 3 - Rochas enderbiticas, charno-enderbiticas e charnockíticas da região de Laje e Mutuípe, no diagrama de Streckeisen (1974)

Figure 3 - Enderbitic, charno-enderbitic and charnockitic rocks of the Laje and Mutuípe region in the Streckeisen (1974) diagram

com prefixo "BJ", que foram extraídas de Barbosa (1986), também foram analisadas na Geosol e no Centro de Pesquisa e Desenvolvimento da Bahia CEPED), seguindo a mesma rotina. As amostras com prefixo "SM" foram retiradas de Wilson (1987). Essas últimas foram coletadas na área em foco juntamente com um dos autores deste artigo e analisadas na Universidade de Oxford, na Inglaterra.
A simples apreciação da tabela 2 permite observar a existência de dois conjuntos de rochas quimicamente distintos, ambos evoluindo de enderbitos para charnockitos. Um primeiro conjunto, denominado de "série baixo Ti (1)", possui valores mais elevados de $\mathrm{MgO}, \mathrm{Al}_{2} \mathrm{O}_{3}, \mathrm{Na}_{2} \mathrm{O}$ e $\mathrm{Sr}$. O segundo conjunto de rochas, chamado de "série alto Ti (2)", possui - além do $\mathrm{TiO}_{2}$ - valores mais elevados de $\mathrm{K}_{2} \mathrm{O}, \mathrm{FeO}$, $\mathrm{Fe}_{2} \mathrm{O}_{3}, \mathrm{MnO}, \mathrm{P}_{2} \mathrm{O}_{5}, \mathrm{Rb}, \mathrm{Zr}$, Y e Elementos Terras Raras. Os nomes "série baixo Ti" e "série alto Ti" foram utilizados neste artigo para comparar uma série em relação à outra. Vale registrar que, apesar de ter sido usada essa nomenclatura, pode-se verificar a existência de superposições de valores de $\mathrm{TiO}_{2}$ entre uma e outra série; no entanto, estas ocorrem entre amostras de rochas de diferentes estágios de evolução da diferenciação magmática e não entre as rochas que apresentam semelhante nível de diferenciação (Tab. 2 e Figs. 4, 5, 6 e 7)

A partir da visualização dessas séries, retornando à petrografia, pode-se observar que as amostras de rochas possuidoras de maior porcentagem de ilmenita, magnetita e hornblenda marrom, coincidentemente correspondem à denominada "série alto Ti". Por sua vez, nas amostras da "série baixo Ti", os opacos estão ausentes ou em pequenas proporções, sendo que a hornblenda marrom é praticamente inexistente, a não ser nos termos menos diferenciados enderbíticos, nos quais ela pode ocorrer como traços (Fornari 1992). Deve-se assinalar que a mineralogia principal da rocha (quartzo, plagioclásio, feldspato alcalino, meso- 

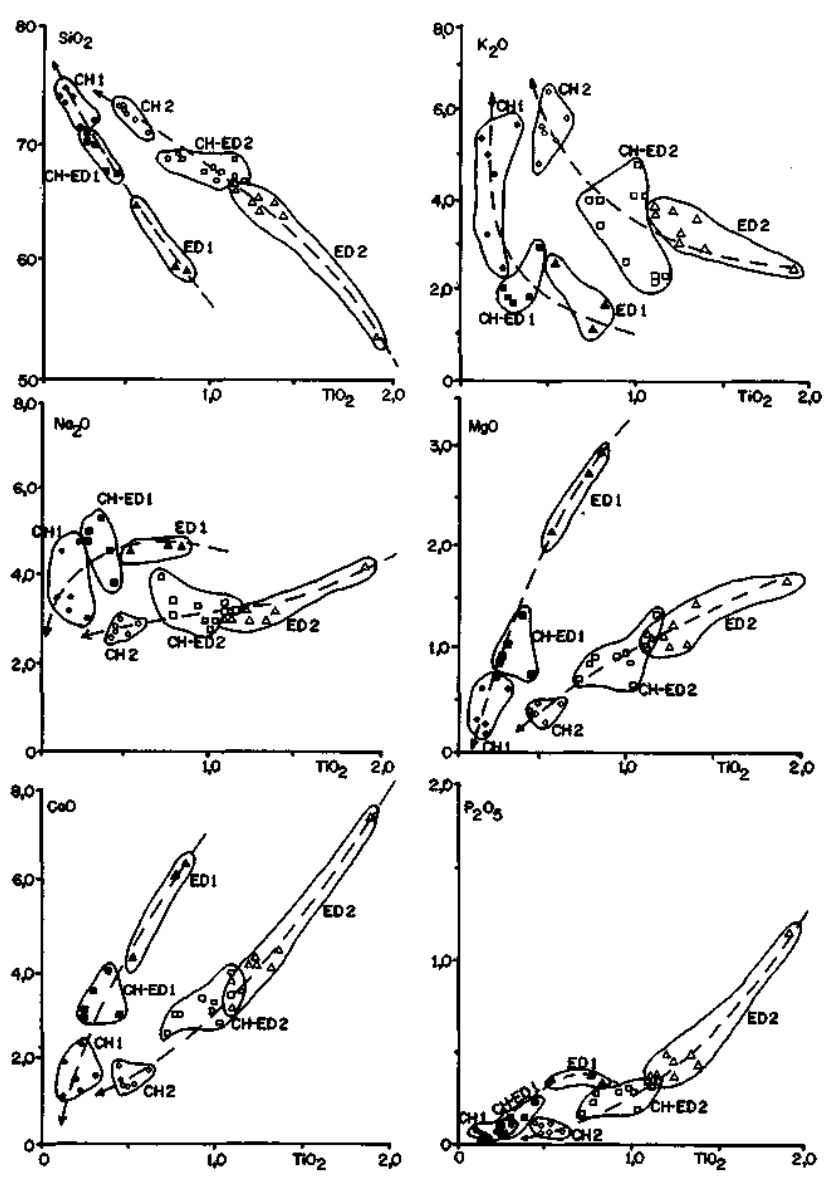

Figura 4 - Trenas de diferenciação magmática das rochas enderbíticas-charnokíticas da região de Laje e Mutuípe, utilizando-se o $\mathrm{TiO}_{2}$ como "índice de diferenciação ". "Série baixo Ti (1) "- EDI/CH-ED1/CH1; "Série alto Ti (2)"- ED2/ $\mathrm{CH}-\mathrm{ED} 2 / \mathrm{CH} 2$

Figure 4 - Magmatic differentiation trends of the enderbitic-charnockitic rocks of the Laje and Mutuípe region, using $\mathrm{TiO}_{2}$ as differentiation index. "Low Ti serie (1)" - ED1/CH-ED1/CH1; "High Ti serie (2)" - ED2/CH$\mathrm{ED} 2 / \mathrm{CH} 2$

pertita e piroxênios) não permite separar as duas séries. Estas puderam ser discriminadas com a composição química e, em seguida, compatibilizadas com a petrografia, por meio dos minerais acessórios. Ainda sobre a comparação entre a petrografia e a litogeoquímica, deve-se assinalar que as rochas da "série alto Ti", possuidoras de maior quantidade de opacos e hornblenda marrom, exibem, além de $\mathrm{TiO}_{2}$, valores mais elevados de $\mathrm{Fe}_{2} \mathrm{O}_{3}$ e $\mathrm{FeO}$, em comparação com a "série baixo Ti". Tal relação pode ser explicada, tendo em vista que o titânio pode estar presente na estrutura da hornblenda marrom e, certamente, combina-se com o ferro para formar a ilmenita. Por outro lado, o $\mathrm{TiO}_{2}$ também pode estar em quantidade considerável na estrutura da magnetita (Deer et al 1966).

A presença das séries "alto e baixo Ti", nas rochas da área, torna-se mais visível com a utilização dos diagramas de discriminação geoquímica de $\mathrm{TiO}_{2}$ versus os demais elementos maiores, menores e traços (Fig. 4). $\mathrm{O} \mathrm{TiO}_{2}$ foi escolhido como índice de diferenciação, não só por ter possibilitado uma boa observação das linhagens magmáticas, mas também por apresentar espectro de variação bastante grande e, sobretudo, por mostrar enriquecimento constante dos termos mais diferenciados (charnockitos) para os menos diferenciados (enderbitos). A figura 4

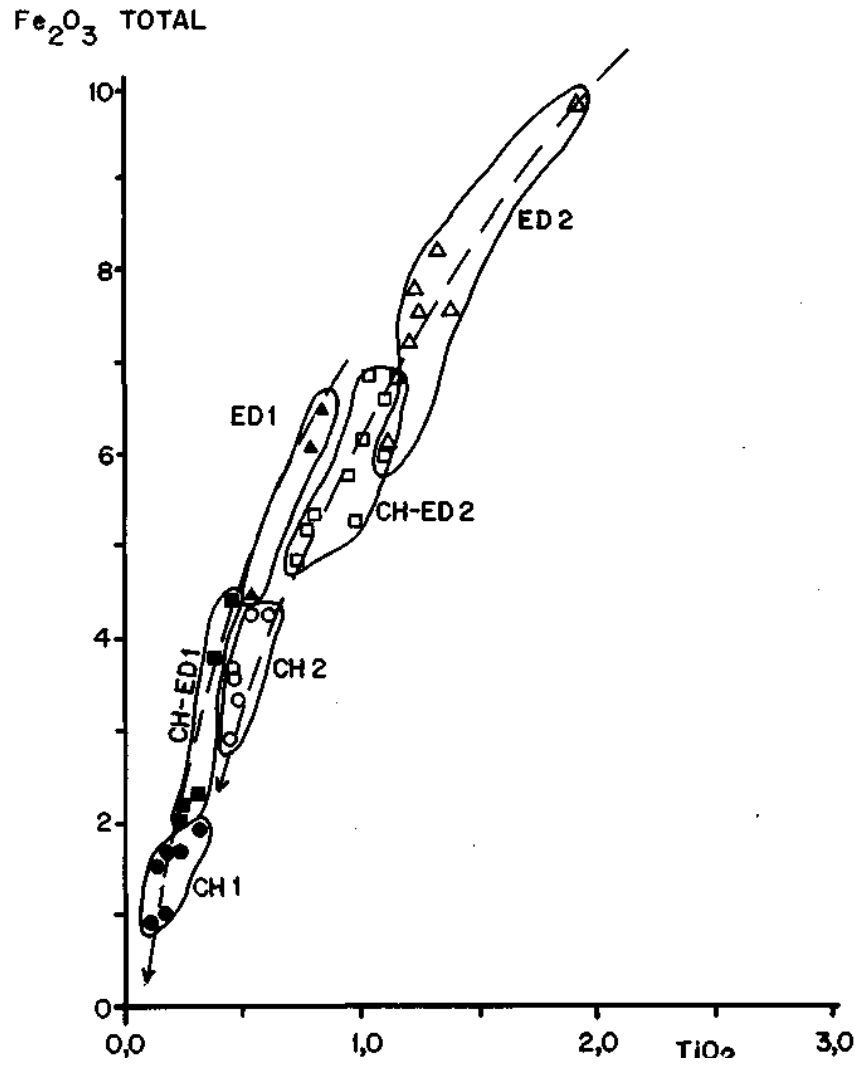

Figura 5 - Trenas de diferenciação magmática das rochas plutônicas pesquisadas. Mesma simbologia que afigura 4 Figure 5 - Magmatic differentiation trends of the studied plutonic rocks. Same simbology as figure 4

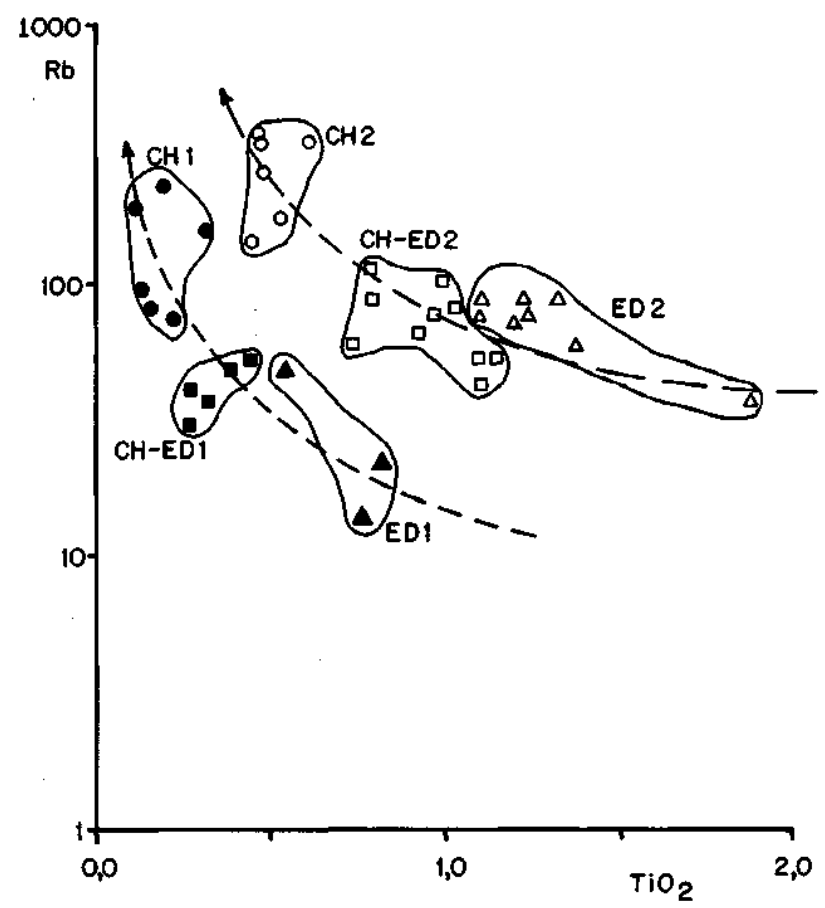

Figura 6 - Trends de diferenciação magmática das rochas enderbíticas-charnockiticas da região de Laje e Mutuípe. O $\mathrm{Rb}$ comporta-se como elemento incompativel durante a diferenciação. Mesma simbologia que afigura 4 Figure 6 - Magmatic differentiation trends of the enderbitic-charnockitic rocks of the Laje and Mutuípe region. Rb behaves as incompatible element during differentiation. Same simbology as figure 4 


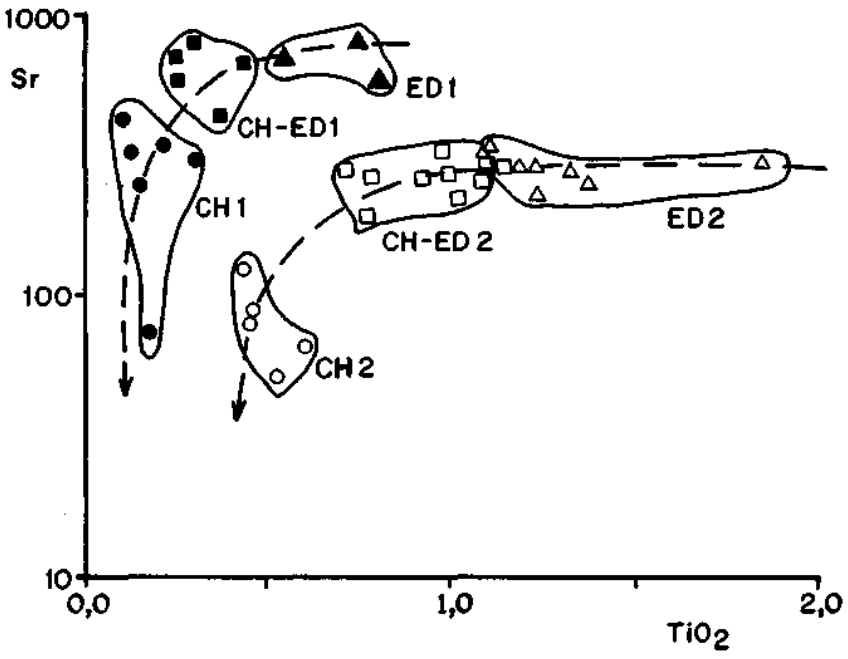

Figura 7 - Trends de diferenciação magmática das rochas plutônicas pesquisadas. O Sr comporta-se como elemento compatível no decurso do processo evolutivo. Mesma simbologia que afigura 4

Figure 7- Magmatic differentiation fremis of the plutonic rocks. Sr behaves as compatible element during the evolution process. Same simbology as figura 4

permite verificar que, mesmo com relação aos elementos considerados móveis durante o metamorfismo, como por exemplo o $\mathrm{K}$ e $\mathrm{Na}$, a presença das duas séries é evidente. Isto demonstra que os enderbitos, charno-enderbitos e charnockitos, apesar de terem sido submetidos a reequilíbrios durante a granulitização, não sofreram significativas mudanças químicas; restaram praticamente intactas suas características plutônicas (Barbosa 1986, Figueiredo 1989, Fornari 1992).

$\mathrm{O} \mathrm{Fe}$, o $\mathrm{Mg}$ e o $\mathrm{Ca}$ apresentam o mesmo comportamento frente aos processos de diferenciação magmática, ou seja , possuem correlação positiva com o Ti (Figs. 4 e 5). Portanto, como era de se esperar, encontram-se maiores proporções de ortopiroxênio (hiperstênio) e clinopiroxênio (augita), nos termos menos diferenciados enderbíticos; analogamente, ocorrem mais elevadas porcentagens de minerais opacos (ilmenita e magnetita).

Nos diagramas das figuras 6 e 7, são mostrados, respectivamente, os comportamentos do $\mathrm{Rb}$ e do $\mathrm{Sr}$ frente aos processos de diferenciação magmática. Assim, relacionando-se o $\mathrm{TiO}_{2}$ versus $\mathrm{Rb}$ observa-se que, no decorrer do processo evolutivo, este elemento-traço comportou-se de maneira incompatível, concentrando-se no líquido, tendo sido incorporado principalmente nos feldspatos alcalinos dos termos mais evoluídos, charnockíticos, de ambas as séries. O Sr, por outro lado, no diagrama $\mathrm{TiO}_{2}$ versus o $\mathrm{Sr}$, mostra um caráter compatível. Ele foi consumido gradativamente no decurso do processo evolutivo, principalmente pela cristalização de plagioclásios. Por consequência, esse elemento é encontrado em menores proporções nos termos mais evoluídos.

A presença das duas séries magmáticas identificadas nos "plútons" enderbíticos-charnockíticos de Laje e Mutuípe é também observada nos gráficos de Terras Raras, sendo destacável que a "série alto Ti" possui valores mais elevados de Terras Raras do que a "série baixo Ti" (Fig. 8). Por sua vez, as razões $\mathrm{Ce}_{\mathrm{N}} / \mathrm{Yb}_{\mathrm{N}}$ que na "série alto Ti" oscilam de 8,1 a 16,6 e na "série baixo Ti" variam de 15,8 a 107,2 mostram que o fracionamento das Terras Raras é maior na "série baixo Ti". Ainda sobre as Terras Raras, seus espectros não só denunciam tendência cálcio-alcalina para o magma

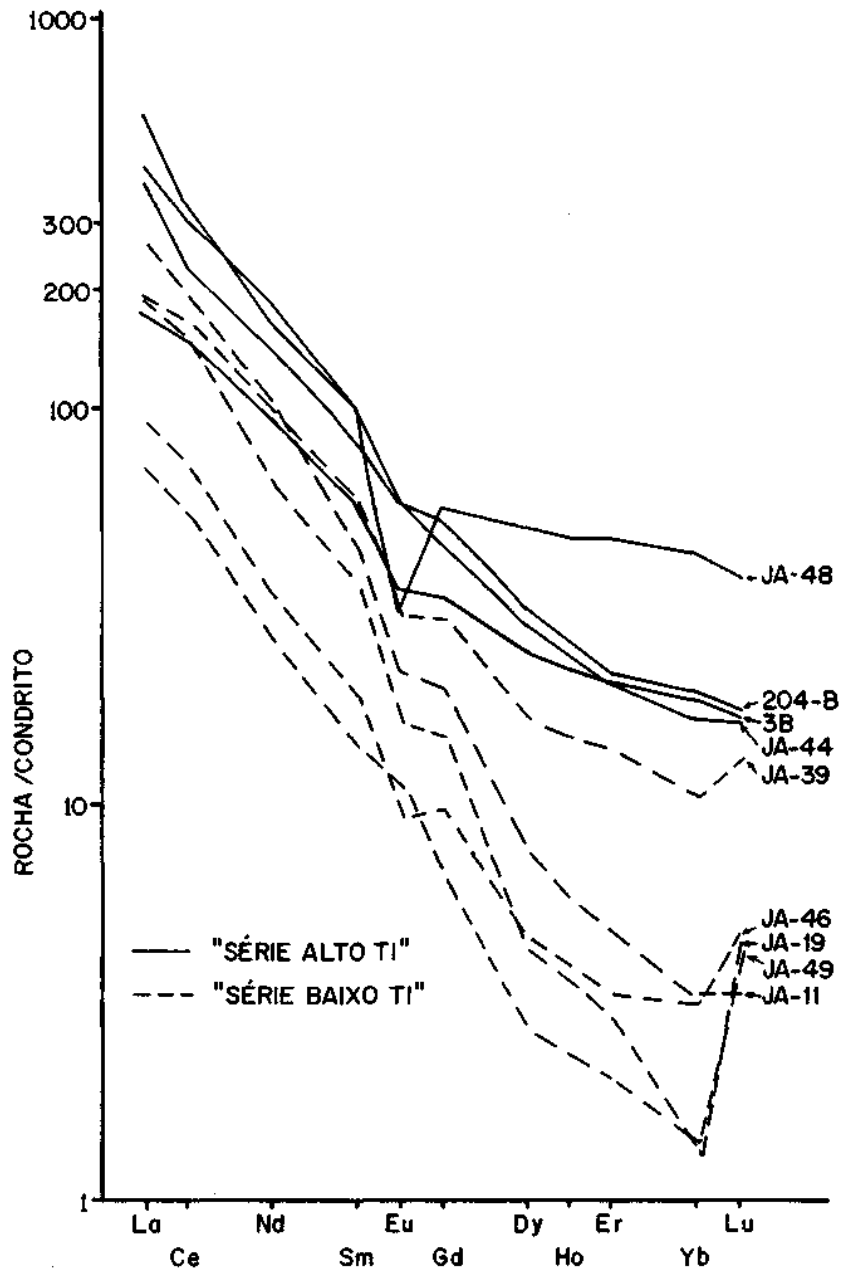

Figura 8 - Espectros de Terras Raras das "séries alto e baixo Ti". A "série alto Ti" possui valores mais elevados de Terras Raras que a "série baixo Ti". Os teores dos Elementos Terras Raras foram normalizados pelo valor do condrito de Evensen et al. (1978)

Figure 8 - Rare Earth spectra of "high and Io w Ti series". The "high Ti series" posseses higher Rare Earth values than "low Ti series". The Rare Earth Elements were chondrite-normalized acording to Evensen et al, (1978)

gerador dessas rochas, como também exibem claro fracionamento das Terras Raras leves em comparação com as pesadas, além de anomalias significativas de Eu (Fig. 8). Por outro lado, a utilização do diagrama de Barker \& Arth (1976) permite confirmar o caráter cálcio-alcalino desses plutonitos (Fig. 9).

CONCLUSÕES As rochas plutônicas enderbíticascharnockíticas, da área pesquisada, são formadas basicamente de mesopertita e/ou feldspato alcalino pertítico, plagioclásio e quartzo, ocorrendo subordinadamente hiperstênio, augita, hornblenda marrom, biotita, ilmenita, magnetita, zircão e apatita.

Ôs dados litogeoquímicos demonstraram a existência de duas séries magmáticas: uma do tipo "alto Ti" e outra do tipo "baixo Ti", ambas cálcio-alcalinas formadas de enderbitos, charno-enderbitos e charnockitos. As séries magmáticas não foram passíveis de separação durante o mapeamento geológico, nem com o uso da petrografia. Isto só foi viável com a utilização da geoquímica, sobretudo quando se considerou o titânio como elemento discriminante 


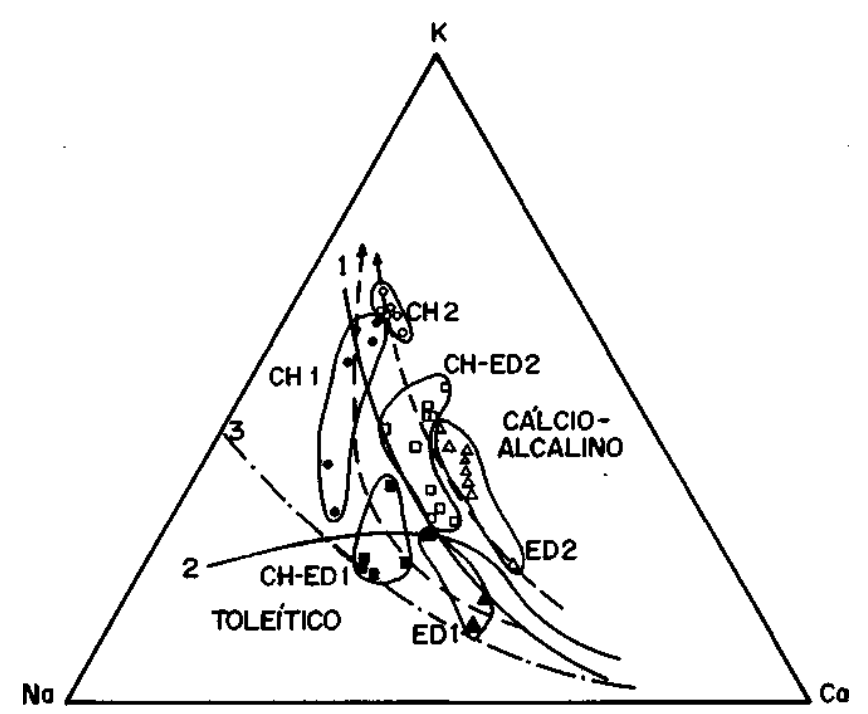

Figura 9 - Caráter cálcio-alcalino alto potássio das rochas pesquisadas. Curva 1: tendência cálcio-alcalina; Curva 2: tendência trondhjemítica; Curva 3: divisão dos campos cálcio-alcalino e toleitico, segundo Tegyey (1979) Figure 9 - Calc-alkaline high-K character of the studied rocks. Curve 1: Calc-alkaline trend; curve 2: trondhjemitic trend; curve 3: division of calcalkaline and toleiitic fields by Tegyey (1979) durante a diferenciação magmática, utilizando-o versus outros elementos em variografia.

Datações pelo método U/Pb, em zircão, utilizando-se a microssonda iônica de alta resolução, têm demonstrado que a "série baixo Ti", de menor maturidade química, cristalizou-se a aproximadamente $2.800 \mathrm{Ma}$ (Alibert \& Barbosa 1992). Esta teria intrudido os granulitos básicos e ácidos ortoderivados, além das rochas supracrustais, situadas a oeste da área, que, segundo os dados radiométricos existentes, possuem idades variando entre 2.900 e $3.200 \mathrm{Ma}$ (Wilson 1987, Wilson et al 1988). A "série alto Ti", por sua vez, de características químicas mais maduras, parece ter sido intrudida nas anteriores, provavelmente logo após $2.800 \mathrm{Ma}$. O plutonismo enderbítico charnockítico parece ter ocorrido concomitantemente com granulitização, cujo pico foi contemporâneo com a intrusão.

Todas as rochas descritas foram submetidas a pelo menos dois episódios de deformação dúctil. O último, mais importante, e que praticamente apagou todos os registros do primeiro, foi regido por cisalhamento simples, progressivo, tendo imprimido as direções de foliação/bandamento mais salientes da área.

Agradecimentos Gostaríamos de agradecer ao $\mathrm{CNPq}$ (Conselho Nacional de Pesquisa), pelo financiamento dessas pesquisas; à CBPM (Companhia Baiana de Pesquisa Mineral), pela confecção de parte das lâminas delgadas; ao prof. dr. Patric Ledru, pelo auxílio na interpretação estrutural da área; e, finalmente, ao Prof. Dr. Mário C.H. Figueiredo, por sugestões feitas sobre as duas sequências magmáticas identificadas na área.

\section{REFERÊNCIAS BIBLIOGRÁFICAS}

ALIBERT, C. \& BARBOSA, J.S.F. 1992. Ages U-Pb determines a Ia "SHRIMP" sur dês zircons du Complexe de Jequié, Cráton de São Francisco, Bahia, Brésil. In: REUNION DÊS CIENCES DE LA TERRE, 14. Toulouse, 1992. Proceedings... Toulouse, Soe. Geol. Fr. p. 4.

BARBOSA, J.S.F. 1986. Constitution Litologique et Metamorphique de Ia Region Granulitique du Sud de Bahia - Brésil. Paris. 401p. (Tese de Doutoramento, Universidade de Paris VI).

BARBOSA. J.S.F. 1990. The granulites of the Jequié Complex and Atlantic Coast Mobile Belt. Southern Bahia - Brazil. An expression of Archean/ Early Proterozoic plate convergence. In: VIELZEUF, P. \& VIDAL, P eds. Granulites and Crustal Evolution. Netherlands, Kluwer Acad. Publ. p. 195-221.

BARBOSA, J.S.F. \& FONTEILLES, M. 1989. Caracterizacão dos protólitos da região granulítica do sul da Bahia - Brasil. Rev. Brás. Geoc.,

BARBOSA J.S.F.; MARINHO, M.M.; SABATE, P. 1992. Geology of the Jequié-Itabuna granulitic belt. In: PEDREIRA, A.J.; MARINHO, M.M.; BARBOSA, J.S.F. eds. Petrologic and Geochronologic Evolution of the Oldest Segments of the São Francisco Cráton, Brazil. Salvador, IGCP. p. 7-28. (Excursion Guidebook, Project 280).

BARKER, F. \& ARTH, J.G. 1976. Generation of trondhjemitic-tonalitic liquids and Archean bimodal trondhjemitic-basal suites. Geology, 4:596-600.

CORDANI, U.G. 1973. Evolução Geológica Pré-Cambriana da Faixa Costeira do Brasil, entre Salvador e Vitória. São Paulo. 98 p. (Tese de Livre Docência, IG/USP).

CORDANI, U.G. \& IYER, S.S. 1979. Geocronological investigation on the precambrian granulite terrain of Bahia, Brazil. Precambrian Rés., 9:255-274.

COSTA, L.A.M. \& MASCARENHAS, J.F. 1982. The high-grade metamorphic terrains in the interval Mutuípe-Jequié: Archean and Lower Proterozoic of East-central Bahia. In: INTERN. SYMP. ARCHEAN AND PROTER. GEOL. EVOL. METAL. Salvador, 1982. Roteiros de Excusão... Salvador, SBG-SME. p. 19-37.

DELHAL, J. \& DEMAIFFE, D. 1985. U-Pb Archean geocronology of the São Francisco Cráton (Eastern Brazil). Rev. Brás. Geoc. 15:55-60.

DEER, W.A.; HÇWIE, R.A.; ZUSSMAN, J. 1966. An Iniroduction to the Rock Forming Minerais. London, Longmans. 528 p.

EVENSEN, N.M.; HAMILTON, P.J.; O'NIONS, R.K. 1978. Rare Earth abundances in chondritic meteorites. Geochim. Cosmochim. Acta, 42:1199-1212

FIGUEIREDO, M.C.H. 1989. Geochemical evolution of eastern Bahia, Brazil: A probable Early Proterozoic subduction-related magmatic are. J. South Am. Earth Sei., 2:131-145.
FIGUEIREDO, M.C.H. \& BARBOSA, J.S.F. 1993. Terrenos metamórficos de alto grau do Cráton do São Francisco. In: DOMINGUEZ, J.M.L. \& MISI, A. eds. O Cráton do São Francisco. Salvador, SBG/SGM/CNPq. p. 63-84.

FORNARI, A. 1992. Petrologia, Geoquímica e Metamorfismo das Rochas Enderbüicas-Charnockiticas da Região de Laje e Mutuipe $・ B A$. Salvador. 116 p. (Dissertação de Mestrado, IG/ÚFBa).

FORNARI, A. \& BARBOSA, J.S.F. 1992a. A suíte enderbítica-charnockítica da região de Mutuípe - Bahia. In: SIMP. REG. GEOL. BAHIA SERGIPE, 1. Salvador, 1992. Anais... Salvador, SBG-BA. v. 1, p. 87-91.

FORNARI, A. \& BARBOSA, J.S.F. 1992b. Geologia, petrografia e litogeoquímica das rochas granulíticas da região de Laje e Mutuípe - Bahia. In: CONGR. BRÁS. GEOL., 37. São Paulo, 1992. Boletim de Resumos Expandidos... São Paulo, SBG. v. 2, p. 44-45.

IYER, S.S.; CHOUDHURI, A.; VASCONCELLOS, M.B.A.; CORDANI, U.G., 1984. Radioactive element distribution in the Archean granulite terrain of Jequié, Bahia, Brazil. Contrib. Mineral. Petrol. 85:95-101.

IYER, S.S.; CHOUDHURI, A.; CORDANI, U.G. 1987. Granulite fácies rocks of Brazil: a review of their geological setting, geochronological evolution, petrographic and geochemical characteristics. J. Geol. Soe india, 29:309-326.

LIMA, M.I.C.; FONSECA, E.G.; OLIVEIRA, E.P.; GHIGNONE, J.I.; ROCHA, R.M.; CARMO, U.F.; SILVA, JM.R.; SIGA JÚNIOR, O., 1982. Folha SD-24, Salvador. In: PROJETO RADAMBRASIL. Rio de Janeiro, Radambrasil. 620 p. (Levantamento de Recursos Naturais 24).

MIRANDA, L.L.F.; SOARES, J.V.; MORAES, A.M.V. 1982. Geologia da região de Ubaira-Santa Inếs. In: CONGR. BRÁS. GEOL., 32. Salvador, 1982. Anais... Salvador, SBG. v. 1, p. 246-259.

MASCARENHAS, J.F. 1973. A geologia do centro-leste do Estado da Bahia In: CONGR. BRÁS. GEOL., 28. Aracaju, 1973. Anais... Aracaju, SBG. p. 35-66.

MASCARENHAS, J.F. 1979. Evolução geotectônica do Pré-Cambriano do Estado da Bahia. In: INDA, H. A. V. \& DUARTE, F. B. eds. Textos Básicos. Salvador, SME/CPM. p. 57-165. (Geologia e Recursos Minerais 2).

MASCARENHAS, J.F. 1981. O embasamento pré-cambriano no Estado da Bahia e sua génese. In: SIMP. CRÁTON DO SÃO FRANCISCO E SUAS FAIXAS MARGINAIS, 1. Salvador, 1981. Anais... Salvador, SBG-BA/SME/CPM. v. 1. p. 34-38.

MIRANDA, L.L.F.; SOARES, J.V.; MORAES, A.M.V. 1982. Geologia da região de Ubaira-Santa Inês. In: CONGR. BRÂS. GEOL., 32. Salvador, 1982. Anais... Salvador, SBG. v. 1, p. 246-259. 
OLIVEIRA, E.P. \& LIMA, M.I.C. 1982. Aspectos petrográficos das rochas granulíticas do Complexo de Jequié e estimativas das condições físicas do metamorfismo. In: CONGR. BRÁS. GEOL., 32. Salvador, 1982. Anais... Salvador, SBG. v. 2, p. 589-662.

OLIVEIRA, E.P.; LIMA, M.I.C; CARMO, U.P; WERNICK, E. 1982. The Archean granulite terrains from east Brazil. Rev. Brás. Geoc., 12:356-368

PEDREIRA, A.J.; ARCANJO, J.B.A.; PEDROSA, C.J.; OLIVEIRA, J.E.; SILVA, B.C.E. 1975. Projeto Bahia - Geologia da Bacia do Rio de Contas. Salvador, DNPM/CPRM. 163 p. (Relatório 3).

SIGHINOLFI, G.P. 1970. Investigation into the deep leveis of the continental crust: petrology and chemistry of granulite fácies terrains of Bahia (Brazil). Atti. Soe. Tose. Nat. Mem, Ser. A., 77:327-341.

SIGHINOLFI, G.P. 1971. Investigation into deep crustal leveis: fractionating effects and geochemical trenas related to high-grade metamorphism. Geochim. Cosmochim Acta, 35:1005-1021.

SIGHINOLFI, G.P. \& SAKAI, T. 1977. Uranium and thorium in archean granulite fácies terrains of Bahia (Brazil). Geochem. J., 11:33-39.

SIGHINOLFI, G.P.; FIGUEIREDO, M.C.H.; FYFE, W.S.; KRONBERG, B.J.; OLIVEIRA, M.A.F.T. 1981. Geochemistry and petrology of the Jequié Granulitic Complex (Brazil): an archean basement complex. Contrib. Mineral. Petrol., 78:263-271.
STRECKEISEN, A. 1974. How should charnockitic rocks be named? In: Geologie dês Domaines Cristalins. Liège, Soe. Geol. Belgique. p. 349-360.

TEGYEY, M. 1979. Utilization de Ia géochimie-majeurs pour Ia cartographie dês terrains cristallins: possibilites dês traitemente automatique dês analyses au BRGM. In: FUGIMORI, S. Composição Química de Rochas e suas Aplicações. Salvador, UFBa, 1990. 306 p

WILSON, N. 1987. Combined Sm- $\mathrm{Nd}, \mathrm{Pb} / \mathrm{Pb}$ and $\mathrm{Rb} / \mathrm{Sr}$ Geocronology and Isotope Geochemistry in Polymetamorphic Precambrian Terranes: Examples from Bahia, Brazil and Channel Island, U.K. Oxford, U.K. p. 64. (Master Thesis, Oxford University).

WILSON, N.; MOORBATH, S.; TAYLOR, P.N.; BARBOSA, J.S.F. 1988 Archean and early Proterozoic crustal evolution in the São Francisco Cráton, Bahia, Brasil. Chem. Geol., 70(1-2):146.

MANUSCRITO A803

Recebido em 11 de novembro de 1993

Revisão do autor em 13 de julho de 1994 Revisão aceita em 16 de julho de 1994 